\title{
Inhibitory effects of Asterina pectinifera extracts on melanin biosynthesis through tyrosinase activity
}

\author{
MIN-HO JEONG ${ }^{3}$, KWANG-MO YANG ${ }^{1}$, JUNG-KI KIM ${ }^{1}$, BYUNG-HYOUK NAM ${ }^{2}$, \\ GI-YONG KIM ${ }^{3}$, SANG-WHA LEE ${ }^{3}$, SU-YEONG SEO ${ }^{3}$ and WOL-SOON JO ${ }^{1}$ \\ ${ }^{1}$ Research Center, Dongnam Institute of Radiological and Medical Sciences; ${ }^{2}$ Test and Certification Team, Marine Bio-Industry \\ Development Center; ${ }^{3}$ Department of Microbiology, College of Medicine, Dong-A University, Busan, Republic of Korea
}

Received August 17, 2012; Accepted September 24, 2012

DOI: $10.3892 /$ ijmm.2012.1181

\begin{abstract}
The control of melanogenesis is an important strategy in the treatment of abnormal skin pigmentation for cosmetic purposes. The aim of the present study was to investigate the anti-melanogenic effect of Asterina pectinifera (A. pectinifera) extracts by cell-free mushroom tyrosinase assay, cellular tyrosinase assay, melanin content assay and the analysis of related protein expression in melan-a cells. A. pectinifera was extracted with $80 \%$ methanol (80-MAP) and further fractionated with hexane (He-AP) and ethyl acetate (EA-AP). In addition, the enzyme extract (En-AP) of A. pectinifera, to which protease was added, was processed. EA-AP and En-AP among A.pectinifera extracts showed strong inhibitory activity against the cell-free mushroom tyrosinase activity. EA-AP and En-AP induced significant inhibition of melanin production and cellular tyrosinase activity. In the action of EA-AP and En-AP on melanogenesis, they reduced the expression of melanogenic genes and proteins including tyrosinase, tyrosinase-related protein-1 (TRP-1) and dopachrome tautomerase (Dct). These results showed that EA-AP and En-AP inhibited melanogenesis by reducing tyrosinase activity and melanin production via subsequent downregulation of tyrosinase-related proteins. The overall results suggest that EA-AP and En-AP among A. pectinifera extracts may be promising candidates for the treatment of hyperpigmentation disorder and useful for self-tanning cosmetic products.
\end{abstract}

\section{Introduction}

Melanogenesis is a physiological process resulting in the synthesis of melanin pigments, which are secreted by melanocytes in the basal layer of the epidermis. Melanin is principally responsible for skin color and plays an important role in the

Correspondence to: Dr Wol-Soon Jo, Research Center, Dongnam Institute of Radiological and Medical Sciences, Jwadong-gil 40, Jangan-eup, Gijang-gun, Busan 619-953, Republic of Korea E-mail: sailorjo@dirams.re.kr

Key words: Asterina pectinifera, hyperpigmentation, melanogenesis, tyrosinase, tyrosinase-related protein-1, dopachrome tautomerase prevention of skin injury under normal physiological conditions (1). However, abnormal pigmentations such as freckles, age spots and melasma could indicate skin problems $(1,2)$. The pigmentary disorders are caused by various factors, including UV radiation, inflammation, estrogens and genetic disorders (1). Melanin synthesis is mediated by melanocytespecific enzymes such as tyrosinase, tyrosinase-related protein (TRP)-1, and TRP-2 or dopachrome tautomerase (Dct) $(3,4)$. On the sequential pathway to melanin formation, tyrosinase is a rate-limiting enzyme that catalyzes tyrosine to 3,4-dihydroxyphenylalanine (L-DOPA) and further oxidizes it to dopaquinone (5). Therefore, melanin production mainly depends on the expression and activation of tyrosinase (6). The modulation of melanogenesis is one of the significant strategies to treat abnormal skin pigmentations through medication and cosmetics (7).

To satisfy the desire for decreased melanogenesis, several cosmetic companies are developing melanogenesis inhibitors and discovering skin-whitening cosmetic preparations. In cosmetic preparations, inhibitors such as kojic acid, arbutin, ascorbic acid and licorice extracts have been used as whitening ingredients (8). In particular, tyrosinase inhibitors may not only be clinically useful for the treatment of some dermatological diseases associated with melanin hyperpigmentation, but they may also be important in cosmetics for depigmentation (9). A great deal of interest has recently focused on deriving tyrosinase inhibitors from a natural source. Several chemical compounds have been reported from plant origins as tyrosinase inhibitors, such as ellagic acid (10), oxyresveratrol (11), chlorophorin and norartocarpanone (12) and the most common natural antibrowning agent is ascorbic acid (13). However, the effect of ascorbic acid against enzymatic oxidation is temporary since it is chemically oxidized to the nonfunctional form, dehydroascorbic acid (13). These problems prompted us to search for safer and more effective melanin formation inhibitors from natural sources.

Marine organisms are rich sources of structurally novel and biologically active metabolites with valuable industrial potential. Therefore, in recent years, numerous marine resources have attracted attention as researchers search for bioactive compounds to develop new cosmetics, drugs and health food. In particular, some efforts have sought to develop new depigmentation agents using biologically active compounds 
obtained from marine organisms (14). Among the marine organisms, the starfish has gradually increased in fish or shellfish farms and can cause serious damage to fish, shellfish, ark shell, abalone, little clam, scallop, that inhabit farms of coastal area (15). It is known that a starfish has very strong reproduction-power, i.e., cutting part of the body as well as the whole body can develop into new starfish. Starfish grow in the sea to the east of Korea; they are known to cause serious damage to shellfish farms, and are known as Asterias amurensis and Asterina pectinifera (A. pectinifera) (16). Some crude extracts of Acanthaster planci, Asterias forbesi and A. pectinifera among starfish are active against influenza $B$ virus in embryonated chicks. It was reported that some extracts obtained from A. pectinifera had antimicrobial and anticancer activities (17) and also exhibited antimicrobial capacities against $B$. subtilis and $S$. aureus $(18,19)$. Moreover, we previously showed that the methanolic extract from A. pectinifera had strong antiinflammatory activity (20). However, little is known about the inhibitory effects of starfish extracts on melanin synthesis via tyrosinase activity.

In this study, we found the candidate fraction which contained potential bioactive compounds such as tyrosinase inhibitor from A. pectinifera extracts and investigated the inhibitory activity of the candidate fraction on melanin biosynthesis through tyrosinase activity in melan-a cells.

\section{Materials and methods}

Chemicals and reagents. L-Tyrosine, L-DOPA, mushroom tyrosinase, phorbol 12-myristate 13-acetate (TPA), 3-(4,5-dimethylthiazol-2-yl)-2,5-diphenyltetrazolium bromide (MTT), ascorbic acid, arbutin and other chemical reagents were purchased from Sigma (St. Louis, MO, USA). RPMI-1640, penicillin/streptomycin solution and trypsin were obtained from Gibco (Gaithersburg, MD, USA).

Preparation of A.pectinifera extracts. For the $80 \%$ methanolic extract (80-MAP), the powdered A. pectinifera (100 g d.w.) was first soaked with $80 \%$ methanol at room temperature and was ultrasonicated (Sonic Dismembrator; Fisher Scientific Inc., Pittsburgh, PA, USA) for $30 \mathrm{~min}$. Then, it was incubated at room temperature for $24 \mathrm{~h}$ and methanolic extracts were filtered by Whatman filter paper (Whatman Lab Sales Ltd., UK) (particle retention, 20-25 $\mu \mathrm{m}$ ) and the filtrates were made into powder by the vacuum rotary evaporator (Tokyo Rikakikai Co., Ltd., Tokyo, Japan) at $40^{\circ} \mathrm{C}$ (Fig. 1A). To give a hexane-soluble fraction (He-AP), hexane $\left(n-\mathrm{C}_{6} \mathrm{H}_{14}, 1: 1\right.$ ratio, $\mathrm{w} / \mathrm{v}$ ) was added into 80-MAP for $24 \mathrm{~h}$ at room temperature (Fig. 1A). The hexane-insoluble residue was partitioned between ethyl acetate-water (2:1 ratio, w/v) to give an ethyl acetate soluble fraction (EA-AP) and a water soluble fraction. The ethyl acetate fraction was dried in a rotary evaporator at $40^{\circ} \mathrm{C}$ to yield a dry extract. The 80-MAP, He-AP and EA-AP were dissolved in dimethyl sulphoxide (DMSO; Sigma). The enzyme extract (En-AP) of A.pectinifera was treated with protease (Protamex ${ }^{\mathrm{TM}}$; Novo Nordisk Co., Bagsvaerd, Denmark) in a dried powder of A.pectinifera. The powdered A. pectinifera (100 g d.w.) was ultrasonicated with distilled water $(1: 2$ ratio, $\mathrm{w} / \mathrm{v})$ for $30 \mathrm{~min}$ and was supplemented with $1 \%$ of protease (to dried weight of sample). The enzyme reactant was incubated at $50^{\circ} \mathrm{C}$ for $3 \mathrm{~h}$ and centrifuged at $10,000 \mathrm{xg}$ for $20 \mathrm{~min}$. The supernatant was adjusted at $\mathrm{pH} 3.0$ with L-tartaric acid until the supernant was a transparent solution. Following centrifugation at $10,000 \mathrm{x}$ g for $20 \mathrm{~min}$, the supernant was readjusted to $\mathrm{pH} 6.0$ with calcium carbonate. The sample was filtered with Whatman filter paper (particle retention, $5 \mu \mathrm{m}$ ) and was then filtered with $0.2 \mu \mathrm{m}$ membrane filter (Advantec MFS, Inc., Dublin, CA, USA) (Fig. 1B). The stock solutions were diluted appropriately with buffer or media at the time of testing and the final concentration of DMSO in test wells was $1 \%$ for cell-free assay and $0.1 \%$ for cell-based assay.

Mushroom tyrosinase assay. In vitro mushroom tyrosinase assay was performed with L-tyrosine and L-DOPA as substrate for tyrosinase activity. Inhibitory activity of each extract against tyrosinase catalysed oxidation of L-tyrosine was determined according to the methods of Chang et al (21) in the presence of each crude extract of A.pectinifera. A volume of $40 \mu \mathrm{l}$ of $1.5 \mathrm{mM}$ substrate (L-tyrosine) dissolved in $0.1 \mathrm{M}$ phosphate buffer (pH 6.8) and $120 \mu \mathrm{l}$ of $0.1 \mathrm{M}$ phosphate buffer, were mixed with $20 \mu \mathrm{l}$ of different concentrations from each extracted sample (80-MAP, He-AP, EA-AP and En-AP). Then, $20 \mu 1$ of mushroom tyrosinase $(2,000 \mathrm{U} / \mathrm{ml}$ in phosphate buffer) were added to initiate the reaction. The assay mixture was incubated at $37^{\circ} \mathrm{C}$ for $15 \mathrm{~min}$. The increase in absorbance at $475 \mathrm{~nm}$ caused by the formation of dopachrome was monitored using a microplate reader (Opsys MR; Dynex Technologies, Ltd., Frankfurt, Germany). The inhibitory effect of each extract on mushroom tyrosinase in L-DOPA oxidation was determined according to Masamoto et al (22) with some modifications. A volume of $100 \mu \mathrm{l}$ of $0.1 \mathrm{M}$ phosphate buffer was mixed with $20 \mu \mathrm{l}$ of different concentrations from each extracted sample (80-MAP, He-AP, EA-AP and En-AP). Then, $20 \mu \mathrm{l}$ of mushroom tyrosinase $(2,000 \mathrm{U} / \mathrm{ml}$ in phosphate buffer) were added to initiate the reaction. The mixture was incubated at $37^{\circ} \mathrm{C}$ for $5 \mathrm{~min}$ and added to $40 \mu \mathrm{l}$ of L-DOPA ( $4 \mathrm{mM}$ in $0.1 \mathrm{M}$ phosphate buffer). The mixture was incubated for $10 \mathrm{~min}$ at $37^{\circ} \mathrm{C}$ and the absorbance at $475 \mathrm{~nm}$ of the reaction mixture was recorded. Ascorbic acid $(500 \mu \mathrm{g} / \mathrm{ml})$ as a positive control was used for assay. The percentage inhibition of tyrosine or L-DOPA oxidation was calculated as follows: \% inhibition $=100-(\mathrm{B} / \mathrm{A} \times 100)$, where $\mathrm{A}=\Delta \mathrm{OD}_{475}$ in $10 \mathrm{~min}$ without sample, and $\mathrm{B}=\Delta \mathrm{OD}_{475}$ in $10 \mathrm{~min}$ with tested sample.

Cell cultures and treatment. Murine melan-a melanocytes were originally derived from C57BL/6 J (black, a/a) mice and were obtained from David Kallenberg (St. George's University of London, UK). Melan-a cells were cultured in RPMI-1640 medium containing $10 \%$ heat-inactivated FBS, $100 \mathrm{U} / \mathrm{ml}$ of penicillin, $100 \mu \mathrm{g} / \mathrm{ml}$ of streptomycin, and $200 \mathrm{nM}$ of phorbol 12 -myristate 13 -acetate (TPA) at $37^{\circ} \mathrm{C}$ in $10 \% \mathrm{CO}_{2}$. The culture medium was changed every 2 days. The cells were harvested by trypsinization when they were approximately $70 \%$ confluent, counted with a haemocytometer and seeded at the appropriate numbers into wells of cell culture plates for further experiments.

Cell viability assay. The number of viable cells was determined by the ability of mitochondria to convert MTT to formazan dye. Melan-a cells were cultured overnight in 96 -well plates, at 

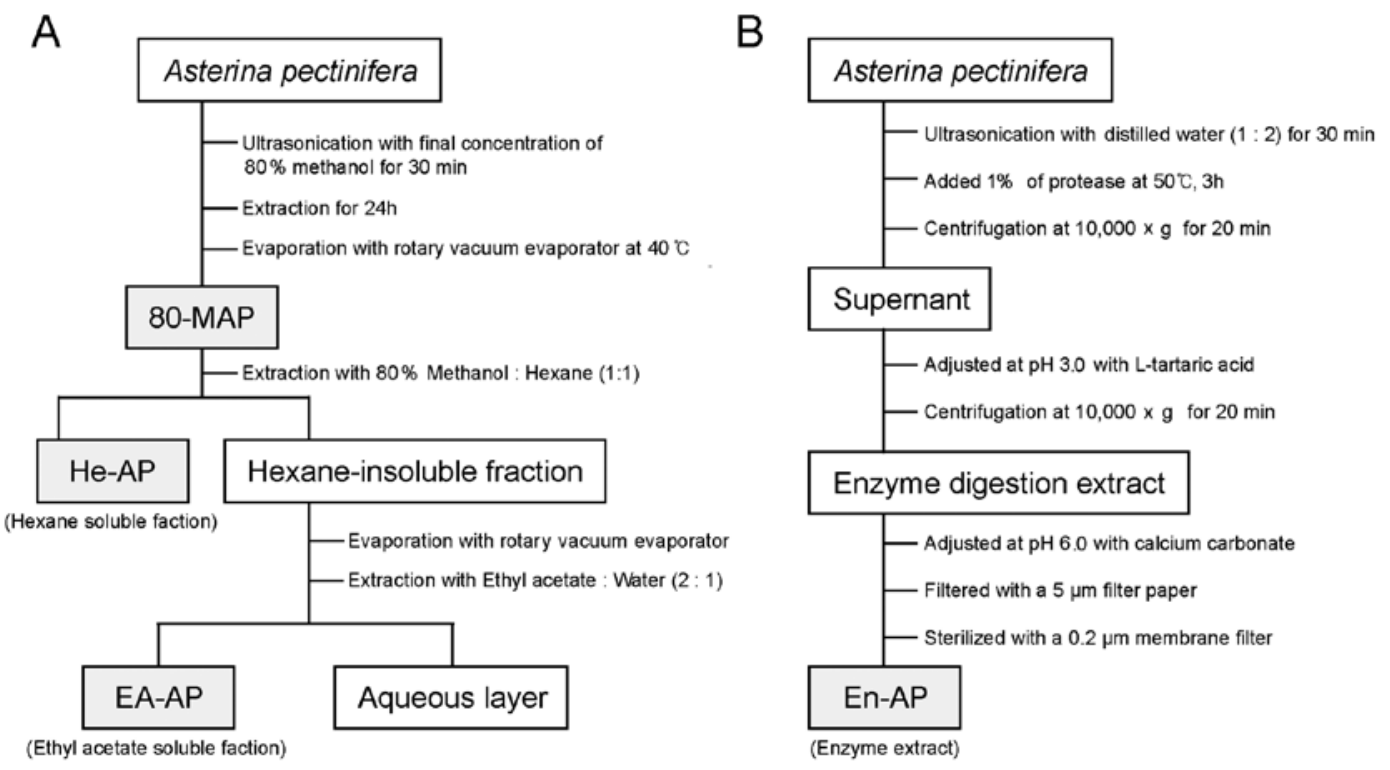

Figure 1. Procedures for the preparation of Asterina pectinifera extracts. Extraction procedure by (A) organic solvents and (B) enzyme digestion, as described in Materials and methods.

a density of $2 \times 10^{4}$ cells $/ 200 \mu 1$ in each well. The next day, the cells were coincubated with various concentrations of EA-AP and En-AP from A. pectinifera for $24 \mathrm{~h}$. Following incubation, the medium was removed and the cells were supplemented with $10 \mu \mathrm{l}$ of $10 \mathrm{mg} / \mathrm{ml}$ MTT into each well. Following incubation for another $4 \mathrm{~h}$ at $37^{\circ} \mathrm{C}$ in a humidified $10 \% \mathrm{CO}_{2}$ atmosphere, the MTT was removed, and cells were lysed with $150 \mu 1 \mathrm{DMSO}$. The absorbance was measured at $550 \mathrm{~nm}$ using a microplate reader.

Measurement of melanin content. Determination of the amount of melanin content was performed using a modified method of Hosoi et al (23). Briefly, melan-a cells were seeded onto a 24 -well plate at a density of $1 \times 10^{5}$ cells/well. Following overnight incubation, the medium was replaced with a medium containing EA-AP and En-AP at different concentrations and incubated for a further $72 \mathrm{~h}$. Arbutin $(250 \mu \mathrm{g} / \mathrm{ml})$ as a positive control was used for the assay. The medium was then removed, the cells washed twice with phosphate-buffered saline (PBS) and harvested by trypsinization using $0.25 \%$ trypsin $/ 0.02 \%$ EDTA in PBS. The harvested cells were pelleted and solubilized in $1 \mathrm{~N} \mathrm{NaOH}$. After centrifugation at 3,000 $\mathrm{x}$ g for $10 \mathrm{~min}$, the optical density at $450 \mathrm{~nm}$ of the resulting supernatant was measured by a microplate reader. The melanin contents per well were calculated, and were expressed as a percentage of the control.

Cellular tyrosinase assay. Cellular tyrosinase activity was measured using the method of Pomerantz (24) with a slight modification. Cells were pretreated with TPA $200 \mathrm{nM}$ for $72 \mathrm{~h}$ and harvested. The cells were then washed with sodium PBS (pH 6.8) and lysed with M-PER mammalian protein extraction reagent (Pierce, Rockford, IL, USA). The lysates were then clarified by centrifugation at $13,000 \mathrm{xg}$ for $15 \mathrm{~min}$ at $4^{\circ} \mathrm{C}$. The ,protein concentration was determined by the Bradford method (Bio-Rad Laboratories, Inc., Hercules, CA, USA) using bovine serum albumin (BSA, St. Louis, MO, USA) as the standard. These proteins were used as a tyrosinase source. A volume of $100 \mu \mathrm{l}$ of $0.1 \mathrm{M}$ phosphate buffer was mixed with $20 \mu \mathrm{l}$ of different concentrations from EA-AP and En-AP. Then, $20 \mu \mathrm{l}$ of the reaction mixture consisting of $40 \mu \mathrm{g}$ protein (adjusted to $100 \mu \mathrm{l}$ with $0.1 \mathrm{M}$ PBS, pH 6.8) was added to initiate the reaction. The mixture was incubated at $37^{\circ} \mathrm{C}$ for $5 \mathrm{~min}$ and added to $40 \mu \mathrm{l}$ of L-DOPA ( $4 \mathrm{mM}$ in $0.1 \mathrm{M}$ phosphate buffer). The mixture was incubated for $10 \mathrm{~min}$ at $37^{\circ} \mathrm{C}$ and the absorbance at $475 \mathrm{~nm}$ of the reaction mixture was recorded. Ascorbic acid $(500 \mu \mathrm{g} / \mathrm{ml})$ as a positive control was used for assay. The percentage inhibition of tyrosine or L-DOPA oxidation was calculated as follows: $\%$ inhibition $=100-(\mathrm{B} / \mathrm{A} \times 100)$, where $\mathrm{A}=\Delta \mathrm{OD}_{475}$ in 10 min without sample, and $\mathrm{B}=\Delta \mathrm{OD}_{475}$ in 10 min with tested sample.

RNA isolationandreal-time PCR. Melan-acells $\left(1 \times 10^{5}\right.$ cells $\left./ \mathrm{ml}\right)$ were plated on $100 \mathrm{~mm}$ culture dishes and incubated in the presence of TPA $200 \mathrm{nM}$. Then, the cells were treated with various concentrations of EA-AP and En-AP for $24 \mathrm{~h}$. Arbutin $(250 \mu \mathrm{g} / \mathrm{ml})$ as a positive control was used for the assay. The cells were harvested and washed twice with ice-cold PBS. Total cellular RNA was prepared using TRIzol solution (Invitrogen, Paisley, UK) according to the manufacturer's instructions. RNA was then precipitated with isopropanol and dissolved in diethylpyrocarbonate-treated distilled water. First-strand cDNA was generated with the oligo(dT) adaptor primers by reverse transcriptase (Takara Bio, Inc., Otsu, Japan). Each specific primer (accession no. of tyrosinase, Mm.238127; accession no. of TRP-1, Mm.30438; accession no. of Dct, Mm.19987; and accession no. of GADPH, Mm.304088) was designed using primer express software from $\operatorname{TaqMan}^{\mathrm{R}}$ Gene expression array (Applied Biosystems, Carlsbad, CA, USA). GAPDH was used as the invariant control. The real-time PCR reaction $(10 \mu \mathrm{l})$ contained $10 \mathrm{ng}$ of reverse transcribed RNA, $200 \mathrm{nM}$ each of forward and reverse primers, and a PCR 

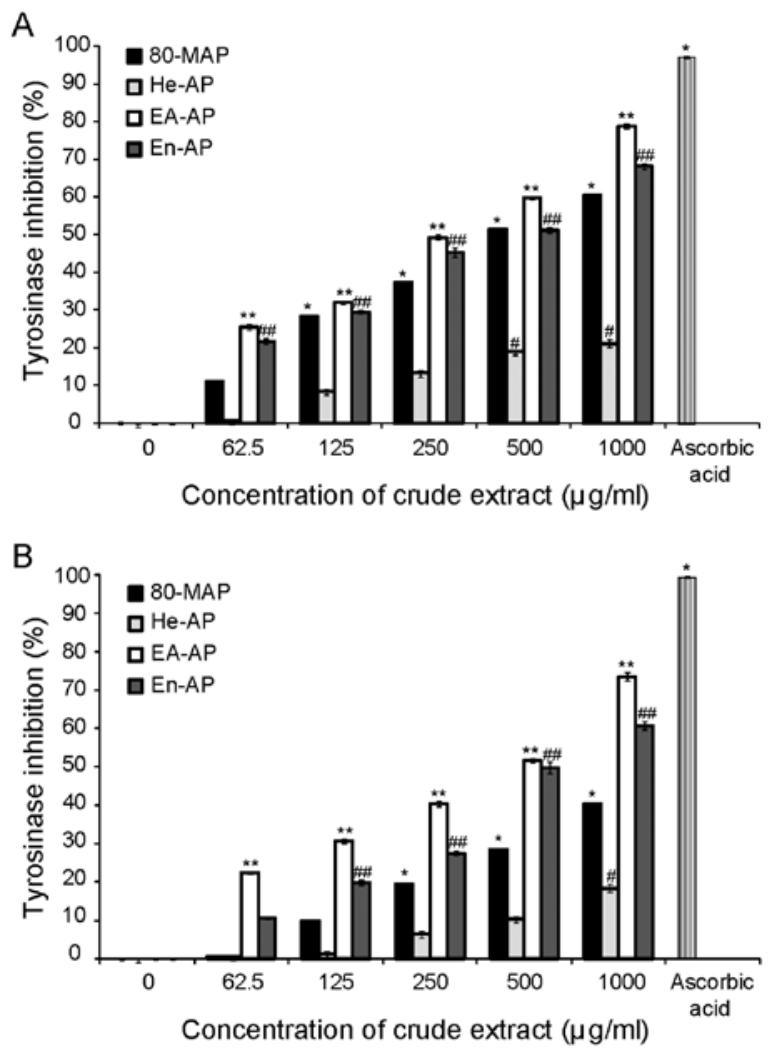

Figure 2. Effect on Asterina pectinifera extracts on mushroom tyrosinase activity. The relative activity of mushroom tyrosinase assayed on (A) L-tyrosine hydroxylation, and (B) 3,4-dihydroxyphenylalanine (L-DOPA) oxidation in the absence or presence of different concentrations of each extract (80-MAP, He-AP, EA-AP and En-AP). Ascorbic acid $(500 \mu \mathrm{g} / \mathrm{ml})$ as a positive control was used. The results are expressed as percentages of control, and the data are the means \pm SD of three independent experiments. ${ }^{* * * *, \#, \# \#)} \mathrm{P}<0.05$ as compared to the untreated control.

master mixture. The reaction was performed using the CFX96 real time system (Bio-Rad, Hercules, CA, USA). All reactions were conducted in triplicate.

Immunoblotting. Melan-a cells $\left(1 \times 10^{5}\right.$ cells $\left./ \mathrm{ml}\right)$ were plated on $100 \mathrm{~mm}$ culture dishes and incubated in the presence of TPA $200 \mathrm{nM}$. The cells were treated with various concentrations of EA-AP and En-AP for $72 \mathrm{~h}$. Arbutin $(250 \mu \mathrm{g} / \mathrm{ml})$ as a positive control was used for the assay. The cells were harvested and washed twice with ice-cold PBS. Then, the cells were resuspended in $200 \mu \mathrm{l}$ ice-cold solubilizing buffer $(300 \mathrm{mM}$ $\mathrm{NaCl}, 50 \mathrm{mM}$ Tris-HCl, pH 7.6, 0.5\% Triton X-100, $1 \mathrm{ml}$ protease inhibitor cocktail) and incubated at $4^{\circ} \mathrm{C}$ for $40 \mathrm{~min}$. The lysates were centrifuged at $14,000 \mathrm{x}$ g for $20 \mathrm{~min}$. Protein concentrations of cell lysates were determined by the Bradford method. Equal amounts of protein were subjected to 7.5-15\% SDS-PAGE for tyrosinase, TRP-1, Dct and $\beta$-actin (Santa Cruz Biotechnology, Inc., Santa Cruz, CA, USA), respectively, and transferred to a nitrocellulose membrane. Immunostaining with antibodies was performed using Super-Signal West Pico enhanced chemiluminescence substrate and detected with LAS-3000PLUS (Fuji Photo Film Co., Kanagawa, Japan).

Statistical analysis. The data are expressed as the means \pm standard deviation (SD). The evaluation of statistical significance
Table I. The inhibitory activity $\left(\mathrm{IC}_{50}\right)$ of mushroom tyrosinase on Asterina pectinifera extracts in mushroom tyrosinase.

\begin{tabular}{lcc}
\hline Extract & $\begin{array}{c}\text { Tyrosinase inhibition } \\
\text { L-tyrosine }(\mu \mathrm{g} / \mathrm{ml})\end{array}$ & $\begin{array}{c}\text { Tyrosinase inhibition } \\
\text { L-DOPA }(\mu \mathrm{g} / \mathrm{ml})\end{array}$ \\
\hline 80-MAP & 500 & $>1,000$ \\
He-AP & $>1,000$ & $>1,000$ \\
EA- AP & 250 & 500 \\
En- AP & 500 & 500 \\
Ascorbic acid & 63 & 175 \\
\hline
\end{tabular}

was performed using Student's t-test or one-way analysis of variance (ANOVA) using the Statistical Package for the Social Sciences (SPSS) statistical software for Windows, version 18.0 (SPSS, Chicago, IL, USA). P $<0.05$ was considered to indicate statistically significant differences.

\section{Results}

A. pectinifera extracts inhibit mushroom tyrosinase activity. To investigate whether A. pectinifera extracts showed any direct inhibitory effect against the key enzyme in the whole melanogenesis, in vitro cell-free mushroom tyrosinase assay was carried out. The effects of each extract (80-MAP, He-AP, EA-AP and En-AP) on mushroom tyrosinase activity are shown in Fig. 2. We observed the inhibitory effect of all extracts on the oxidation of tyrosine and L-DOPA by mushroom tyrosinase in a dose-dependent manner. However, 80-MAP and He-AP showed less inhibitory activity of mushroom tyrosinase than EA-AP or En-AP. A positive control, ascorbic acid, showed strong tyrosinase inhibition, as expected. The EA-AP and En-AP showed less inhibitory activity of mushroom tyrosinase than ascorbic acid at the maximum concentration. In addition, the $\mathrm{IC}_{50}$ of EA-AP and En-AP was 250 and $500 \mu \mathrm{g} / \mathrm{ml}$ for L-tyrosine and $500 \mu \mathrm{g} / \mathrm{ml}$ for L-DOPA, respectively (Table I). Ascorbic acid substantially inhibited the enzyme activity with an $\mathrm{IC}_{50}$ value of $63 \mu \mathrm{g} / \mathrm{ml}$ for L-tyrosine and $175 \mu \mathrm{g} / \mathrm{ml}$ for L-DOPA (Table I) and also showed inhibitory activity $>95 \%$ at $500 \mu \mathrm{g} / \mathrm{ml}$ when compared to untreated control in L-tyrosine and L-DOPA. Taken together, our results demonstrated that EA-AP and En-AP among A. pectinifera extracts have the highest inhibitory effect on mushroom tyrosinase activity.

EA-AP and En-AP induce cell cytotoxicity in melan-a cells. Based on the results of the enzymatic assay, we determined EA-AP and En-AP among A. pectinifera extracts for effective anti-melanogenic activity. Thus, to exclude the possibility that inhibitory effects of EA-AP and En-AP on melanogenesis might be caused by the inhibition of melan-a cell growth, we compared the number of cell growth in the presence and absence of these extracts. We observed the cell viability with MTT assay after treatment of EA-AP and En-AP with different concentrations. After treatment, $50 \%$ of cell viability presenting concentration $\left(\mathrm{IC}_{50}\right.$ values) of EA-AP was $125 \mu \mathrm{g} / \mathrm{ml}$ while the $\mathrm{IC}_{50}$ of En-AP was over $500 \mu \mathrm{g} / \mathrm{ml}$ at tested maximum concentrations (Fig. 3 and Table II). A positive control, the $\mathrm{IC}_{50}$ of arbutin, was $1,041 \mu \mathrm{g} / \mathrm{ml}$ and it induced no cytotoxicity at 
Table II. Effects of EA- AP and En- AP on melanin production and cellular tyrosinase activity of melan-a cells.

\begin{tabular}{lccc}
\hline Extract & $\begin{array}{c}\text { Cytotoxicity } \\
\mathrm{IC}_{50}(\mu \mathrm{g} / \mathrm{ml})^{\mathrm{a}}\end{array}$ & $\begin{array}{c}\text { Melanin synthesis } \\
\mathrm{IC}_{50}(\mu \mathrm{g} / \mathrm{ml})^{\mathrm{b}}\end{array}$ & $\begin{array}{c}\text { Cellular tyrosinase activity } \\
\mathrm{IC}_{50}\left(\mu \mathrm{g} / \mathrm{ml}^{\mathrm{b}}\right.\end{array}$ \\
\hline EA-AP & 125 & 31.3 & 31.3 \\
En-AP & $>500$ & 250 & 250 \\
Arbutin & 1,041 & 63 & - \\
Ascorbic acid & - & - & 250 \\
\hline
\end{tabular}

${ }^{\mathrm{a}} 50 \%$ cell cytotoxicity concentration; ${ }^{\mathrm{b}} 50 \%$ inhibitory concentration.

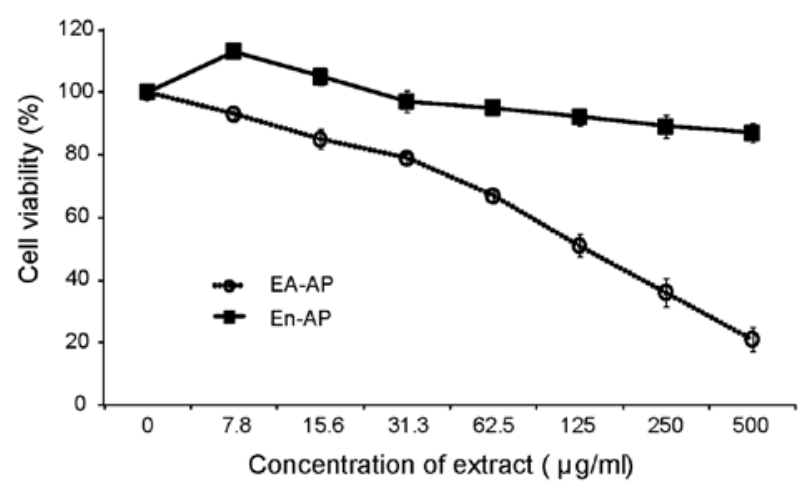

Figure 3. Effect of EA-AP and En-AP on melan-a cell viability. Melan-a cells were treated with various concentrations of EA-AP and En-AP for 24 h. Cell viability was determined using an MTT assay. Each percentage value in the treated cells was calculated with respect to that in the control cells. The results are expressed as percentages of control, and the data are the means \pm SD of three independent experiments.

below $500 \mu \mathrm{g} / \mathrm{ml}$ (data not shown). These results showed that EA-AP induced more cell cytotoxicity than En-AP. Therefore, in this study, we tested further experiments such as melanin synthesis, cellular tyrosinase activity, related gene and protein expression in melan-a cells at concentrations below $\mathrm{IC}_{50}$ of EA-AP and En-AP.

EA-AP and En-AP reduce melanin synthesis and cellular tyrosinase activity in melan-a cells. To evaluate the inhibitory effect of EA-AP and En-AP on melanin content and cellular tyrosinase activity, melan-a cells were treated with different concentrations of these extracts. The inhibitory effect of EA-AP and En-AP on melanin content is shown in Fig. 4. The levels of melanin in the melan-a cells were reduced significantly as a result of the EA-AP (Fig. 4A) and En-AP treatment (Fig. 4B) when compared to the TPA-treated control group. In addition, to measure cellular tyrosinase activity, instead of using mushroom tyrosinase, cell lysates prepared from the melan-a cells treated with TPA were used as a tyrosinase source. The EA-AP and En-AP showed an inhibitory effect on cellular tyrosinase activity in a dose-dependent manner (Fig. 5). The 50\% inhibitory concentration of melanin secretion and cellular tyrosinase activity in melan-a cells was approximately $31.3 \mu \mathrm{g} / \mathrm{ml}$ of EA-AP and $250 \mu \mathrm{g} / \mathrm{ml}$ of En-AP (Table II). Moreover, the effective concentration of En-AP was only slightly cytotoxic to melan-a cells while EA-AP induced cytotoxicity in a dose-dependent manner. Arbutin and ascorbic
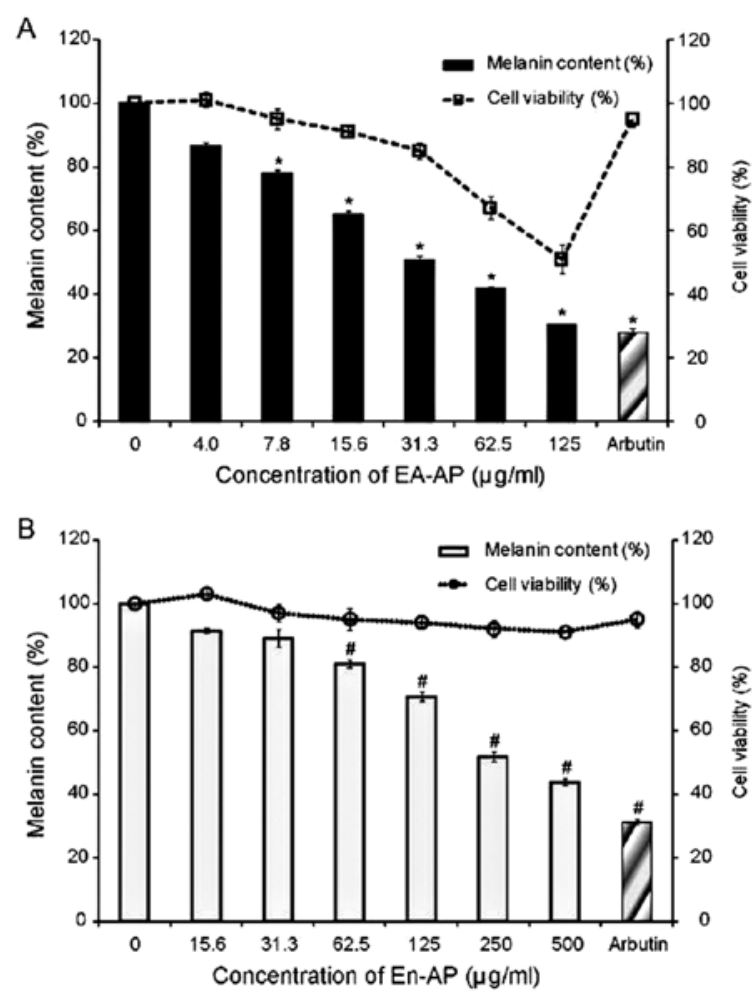

Figure 4. Effect of (A) EA-AP and (B) En-AP on cellular melanin synthesis in melan-a cells. Cells were treated with various concentrations of EA-AP and En-AP in the presence of TPA $(200 \mathrm{nM})$. Arbutin $(250 \mu \mathrm{g} / \mathrm{ml})$ was used as a positive control. Each percentage value for the treated cells was reported relative to that of the control cells. The results are expressed as percentages of control, and the data are the means \pm SD of three independent experiments. ${ }^{*, \#} \mathrm{P}<0.05$ as compared to the untreated control.

acid as a positive control showed a significant reduction of the melanin secretion and cellular tyrosinase activity $(\mathrm{P}<0.05)$ (Figs. 4 and 5), respectively. These results suggest that the inhibitory effect of EA-AP and En-AP on melanin synthesis appear to be well-correlated with the measurement of mushroom tyrosinase activity and cellular tyrosinase activity.

EA-AP and En-AP suppress melanogenesis-related gene and protein expression. To investigate whether EA-AP and En-AP affect the expression of melanogenesis-related proteins including tyrosinase, TRP-1 and Dct, these proteins levels were examined in melan-a cells in the presence of TPA using western blot analysis after treating with various concentrations of EA-AP and En-AP for $72 \mathrm{~h}$. Levels of melanogenesis-related 

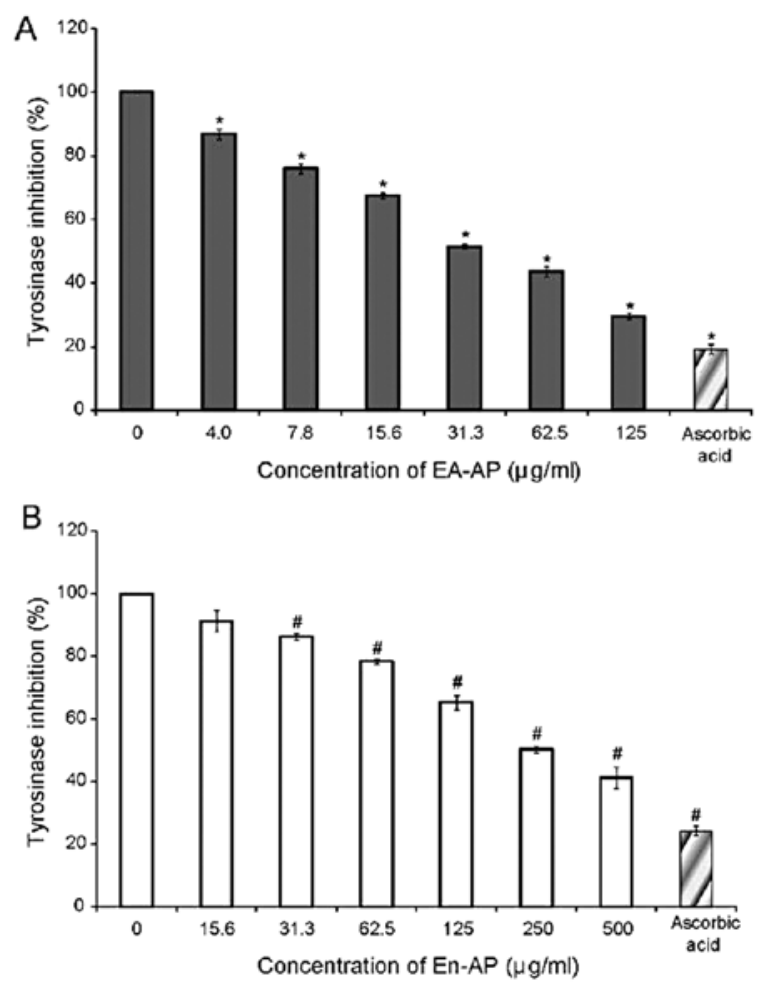

Figure 5. Effect of EA-AP and En-AP on cellular tyrosinase activity in melan-a cells. Cells were treated with TPA $(200 \mathrm{nM})$. The cell lysates were separated and the protein concentration was determined. These proteins were used as a tyrosinase source. The relative activity of extra cellular tyrosinase assayed on 3,4-dihydroxyphenylalanine (L-DOPA) oxidation in the absence or presence of different concentrations of (A) EA-AP and (B) En-AP. Ascorbic acid $(500 \mu \mathrm{g} / \mathrm{ml})$ as a positive control was used. Each percentage value for the treated cells was reported relative to that of the control cells. The results are expressed as percentages of control, and the data are the means \pm SD of three independent experiments. ${ }^{*, t} \mathrm{P}<0.05$ as compared to the untreated control.

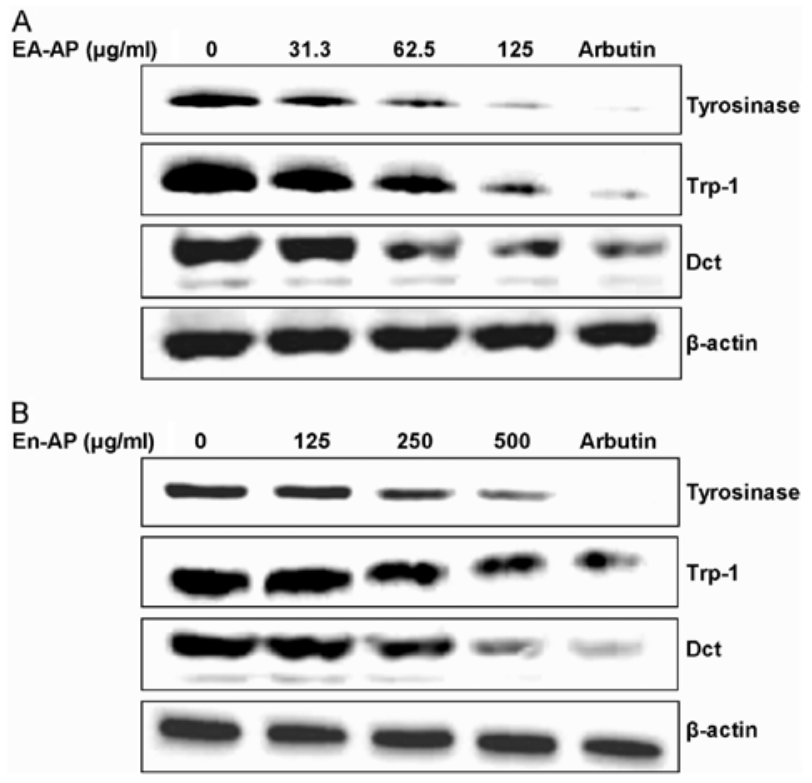

Figure 6. Effect of EA-AP and En-AP on the expression of melanogenesisrelated proteins in melan-a cells. The cells were treated with the indicated concentrations of EA-AP and En-AP in the presence of TPA stimulation for $72 \mathrm{~h}$. Arbutin $(250 \mu \mathrm{g} / \mathrm{ml})$ was used as a positive control. The expression levels of tyrosinase, TRP-1 and Dct proteins by (A) EA-AP and (B) En-AP were measured by western blotting using specific antibodies. Equal protein loading was checked by $\beta$-actin.
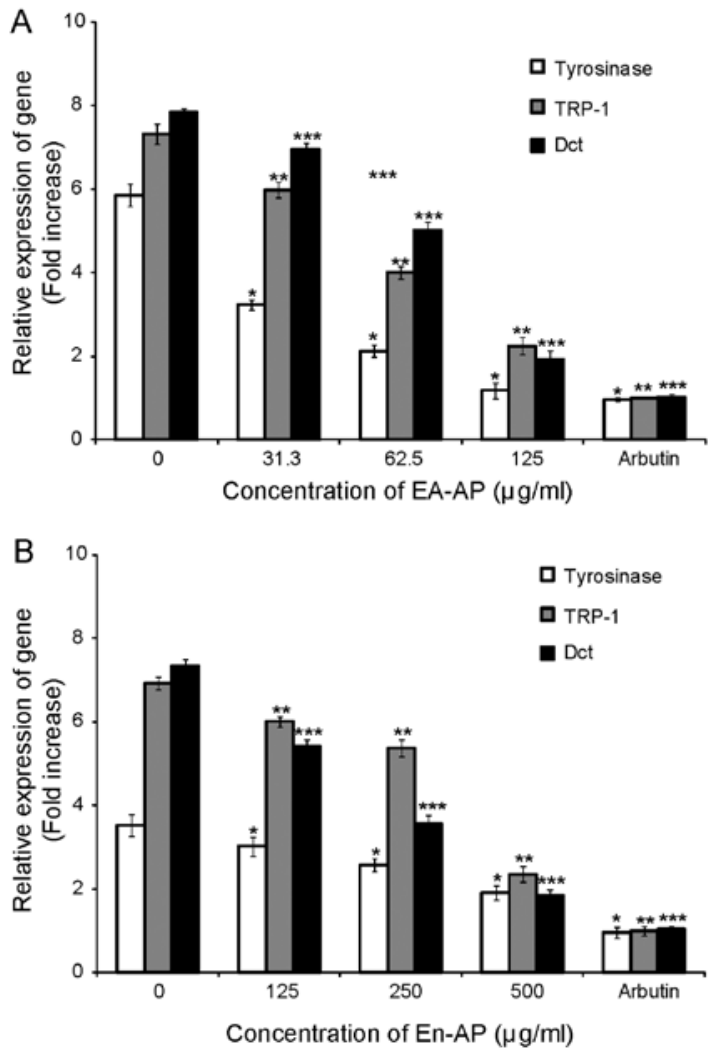

Figure 7. Effect of EA-AP and En-AP on the expression of melanogenesisrelated genes in melan-a cells. The cells were treated with the indicated concentrations of EA-AP and En-AP in the presence of TPA stimulation for $24 \mathrm{~h}$. Arbutin $(250 \mu \mathrm{g} / \mathrm{ml})$ was used as a positive control. The expression levels of tyrosinase, TRP-1 and Det gene by (A) EA-AP and (B) En-AP were measured by real-time PCR analysis using specific primers. mRNA signal was normalized to GAPDH mRNA signal. ${ }^{* * * * * * * *} \mathrm{P}<0.05$ as compared to the untreated control.

protein, tyrosinase, TRP-1 and Dct were reduced after EA-AP (Fig. 6A) and En-AP (Fig. 6B) treatment in a dose-dependent manner. To examine whether the inhibition of tyrosinaserelated protein expression by EA-AP and En-AP was due to decreased level transcription, we tested real time PCR using specific primers. The mRNA level of tyrosinase, TRP-1 and Dct was significantly decreased by treatment with EA-AP $(\mathrm{P}<0.05)$ (Fig. 7A) and En-AP $(\mathrm{P}<0.05)$ (Fig. 7B). Arbutin as a positive control showed a significant reduction of gene and protein levels of tyrosinase, TRP-1 and Dct in a dose-dependent manner while only TPA-treated cells markedly increased gene and protein levels in tyrosinase, TRP-1 and Dct (Figs. 6 and 7). These results indicate that the suppressive activity of EA-AP and En-AP on melanogenesis is linked to the downregulation of tyrosinase expression signaling pathways.

\section{Discussion}

In Asian countries, women are concerned with skin whitening as having whiter skin is often seen to be a superior standard of beauty (25). As a number of women worry about skin pigmentation, effective agents for the improvement of hyperpigmentation have been researched for skin whitening products (26). These foregoing attributes prompted the present hypothesis that a marine natural product might be 
valuable as a cosmetic component to improve the appearance of hyperpigmentation. We intended in this study to find new whitening materials from A. pectinifera, a marine organism that would also have significance insofar as we would obtain bioactive materials by using starfish which would be discarded after collection from the sea. Therefore, we investigated the potential whitening effect of $A$. pectinifera extracts (80-MAP, He-AP, EA-AP and En-AP) and also demonstrated the effect of each extract on melanin biosynthesis through tyrosinase activity which is a standard model for assessing regulators of melanogenesis since tyrosinase is the key enzyme in melanogenesis, initiating a cascade of reactions which convert tyrosine to the biopolimer melanin (27).

Tyrosinase (polyphenol oxidase) plays rate-limiting roles in the production of melanin by melanocytes. Melanin pigment, responsible for visible skin color, is formed through a series of oxidative reactions involving the amino acid, tyrosine. Tyrosinase catalyses three main steps in melanogenesis; the hydroxylation of L-tyrosine to L-dihydroxyphenylalanine (L-DOPA), the oxidation of L-DOPA to dopaquinone, and the additional oxidation of 5,6-dihydroxyindole to indol-quinone (28). Almost all factors affecting melanin production exert their action either directly or indirectly via stimulation of tyrosinase and the most common target for skin-lightening activities is tyrosinase inhibition (29). Indeed, recently, a great deal of interest has been on deriving tyrosinase inhibitors from plant origin and anti-melanogenesis activities of several herbal medicines have been evaluated by their ability to inhibit tyrosinase (30).

In this study, several fractions of powdered dried A. pectinifera were extracted with solvents of different polarity and tested for their possible anti-melanogenesis or skin-whitening properties using the inhibition of mushroom tyrosinase activity in a cell-free system as screening assays. Our data revealed that the methanolic extract (80-MAP) and enzymatic extract (En-AP) inhibited mushroom tyrosinase activity among $A$. pectinifera extracts and particularly the separated ethyl acetate fraction (EA-AP) from 80-MAP had a strong suppression of tyrosinase activity. However, hexane fraction (He-AP) showed less inhibitory activity than EA-AP (Fig. 2 and Table I). In addition, EA-AP and En-AP inhibited cellular tyrosinase activity as well as melanin production in melan-a cells (Figs. 4 and 5). These results suggest that EA-AP and En-AP among A. pectinifera extracts may contain potential skin-whitening materials that could induce reduction of melanogenesis in melan-a cells by reduction of tyrosinase activity.

Dooley (31) previously speculated that a desirable skin-whitening agent should inhibit melanin synthesis in melanosomes by acting specifically to reduce the synthesis or activity of tyrosinase with little or no cytotoxicity. In this study, En-AP appeared to have little cytotoxic as well as anti-melanogenic activity among $A$. pectinifera extracts while EA-AP induced some cytotoxicity under TPA-stimulated melan-a cells (Fig. 3). Accordingly, EA-AP at higher concentration levels (250 and $500 \mu \mathrm{g} / \mathrm{ml}$ ) was not used further due to its greater cytotoxicity on the melan-a cells. These data demonstrate that En-AP contains safer materials for potential skin-whitening activity than EA-AP due to the slight cytotoxic effects of EA-AP at the higher concentrations. In mammals, melanogenesis occurs in melanocytes after differentiation of the nonpigmented precursors, melanoblasts. Three melanocyte-specific enzymes, including tyrosinase, TRP-1 and Dct (TRP-2), are involved in the enzymatic process that converts tyrosine to melanin pigments (32). In particular, there are two tyrosinase-related proteins, TRP-1 and Dct (TRP-2), which are structurally related to tyrosinase and share approximately $40 \%$ amino acid homology, suggesting that they originated from a common ancestral gene (33). As TRP-1 forms a complex with tyrosinase, it is possible that TRP-1 plays a role in tyrosinase activation and/or stabilization (34). TRP-1 also plays a role in melanosomal biogenesis, as suppression of TRP-1 expression is associated with structurally abnormal melanosomes (35). TRP-2 complexes with tyrosinase and also with TRP-1 (36). TRP-2 converts DOPAchrome to the carboxylated derivative dihydroxyindole-2-carboxylic acid (DHICA) during one of the later stages of melanin biosynthesis (37). Indeed, TRP-1 and TRP-2 have been demonstrated to increase tyrosinase stability (38) and are responsible for the induction of melanin synthesis $(29,39,40)$. Both EA-AP and En-AP reduced melanogenic proteins, tyrosinase, TRP-1 and Dct (TRP-2) (Fig. 6), and also the inhibitory effects of EA-AP and En-AP on melanogenesis likely resulted from suppressed gene expression of tyrosinase, TRP-1 and Dct (TRP-2) (Fig. 7).

In conclusion, we suggest that EA-AP and En-AP from A. pectinifera extracts inhibit melanin synthesis via subsequent downregulation of tyrosinase-related proteins. Therefore, EA-AP and En-AP may be useful candidates for the development of potential therapeutic agents for hyperpigmentation treatment, and may be an effective component in whitening and lightening cosmetics. We will further separate single compounds from EA-AP fraction of A.pectinifera and explore the inhibition of melanin synthesis via MITF downregulation and related signaling pathways.

\section{Acknowledgements}

We thank Dr Dorothy C. Bennett and Dr David Kallenberg (St. George's University of London) for their helpful discussions and gifts of melan-a. This research was supported by the 2012 National R\&D Program through the Dongnam Institute of Radiological and Medical Sciences (DIRAMS) funded by the Ministry of Education, Science and Technology (50493-2012) and the Technology Development Program for Agriculture and Forestry (610003-03-1-SB110), Ministry for Food, Agriculture, Forestry and Fisheries, Republic of Korea.

\section{References}

1. Pawelek JM, Chakraborty AK, Osber MP and Bolognia JL: Ultraviolet light and pigmentation of the skin. Cosmetics \& Toiletries Magazine 107: 61-68, 1992.

2. Briganti S, Camera E and Picardo M: Chemical and instrumental approaches to treat hyperpigmentation. Pigment Cell Res 16: 101-110, 2003.

3. Kobayashi T, Urabe K, Winder A, et al: Tyrosinase related protein 1 (TRP1) functions as a DHICA oxidase in melanin biosynthesis. EMBO J 13: 5818-5825, 1994

4. del Marmol V and Beermann F: Tyrosinase and related proteins in mammalian pigmentation. FEBS Lett 381: 165-168, 1996.

5. Lerner AB, Fitzpatrick TB, Calkins E and Summerson WH: Mammalian tyrosinase; preparation and properties. J Biol Chem 178: 185-195, 1949.

6. Slominski A, Tobin, DJ, Shibahara S and Wortsman J: Melanin pigmentation in mammalian skin and its hormonal regulation. Physiol Rev 84: 1155-1228, 2004. 
7. Jones K, Hughes J, Hong M, Jia Q and Orndorff S: Modulation of melanogenesis by aloesin: a competitive inhibitor of tyrosinase. Pigment Cell Res 15: 335-340, 2002.

8. Maeda $\mathrm{K}$ and Fukuda $\mathrm{M}$ : In vitro effectiveness of several whitening cosmetic components in human Melanocyte. J Soc Cosmet Chem 4: 361-368, 1991.

9. Shiino M, Watanabe Y and UmezawaK: Synthesis of N-substituted $\mathrm{N}$-nitrosohydroxylamines as inhibitors of mashroom tyrosinase. Bioorg Med Chem 9: 1233-1240, 2001.

10. Shimogaki H, Tanaka Y, Tamai H and Masuda M: In vitro and in vivo evaluation of ellagic acid on melanogenesis inhibition. Int J Cosmetic Sci 22: 291-303, 2000.

11. Kim DS, Kim SY, Chung JH, Kim KH, Eun HC and Park KC: Delayed ERK activation by ceramide reduces melanin synthesis in human melanocytes. Cell Signal 14: 779-785, 2002.

12. Shimizu K, Kondo R, Sakai K, Lee SH and Sato H: The inhibitory components from Artocarpus incisus on melanin biosynthesis Planta Med 64: 408-412, 1998.

13. Komthong P, Igura $\mathrm{N}$ and Shimoda M: Effect of ascorbic acid on the odours of cloudy apple juice. Food Chem 100: 1342-1349, 2007.

14. Cha SH, Ko SC, Kim D and Jeon YJ: Screening of marine algae for potential tyrosinase inhibitor: those inhibitors reduced tyrosinase activity and melanin synthesis in zebrafish. J Dermatol 38 : 354-363, 2010.

15. Park MS and Kim BY: Feeding behaviour of the starfish, Asterias amurensis (LUTKEN). Bull Fish Res Dev Agency 34: 1-174, 1985.

16. Park SW, Kim TH and Oh HK: A study on the development of the extermination gear for starfish, Asterias amurensis and its efficiency. J Korean Soc Fish Technol 33: 166-172, 1997.

17. Seo JK: Conformation and biological activity of Mastoparan B and its analogs: isolation and characterization of the biological substances from Inshore Hagfish (Eptatretus burgeri) skin and starfish (Asterina pectinifera). (Thesis) Pukyong National University, 1997.

18. Cho SY, Kang HJ, Joo DS, Jeon JK, Oh MH and Kim JS: Seperation and identification of nature antimicrobial agent from starfish. 47th Conference of Korean Society. J Food Science Nutr: 695-701, 2000.

19. Cho SY, You BJ, Chang MH, Lee SJ, Sung NJ and Lee EH: Screening for antimicrobial compounds in unused marine resources by the paper disk method. Korean J Food Sci Technol 26: 261-265, 1994 (In Korean).

20. Jo WS, Choi YJ, Kim HJ, Nam BH, Lee GA, Seo SY, Lee SW and Jeong MH: Methanolic extract of Asterina pectinifera inhibits LPS-induced inflammatory mediators in murine macrophage. Toxicol Res 6: 1-82, 2010

21. Chang TS, Ding HY, Tai SSK and Wu CY: Mushroom tyrosinase inhibitory effects of isoflavones isolated from soygerm koji fermented with Aspergillus oryzae BCRC 32288. Food Chem 105: 1430-1438, 2007.

22. Masamoto Y, Ando H, Murata Y, Shimoishi YTM and Takahata K Mushroom tyrosinase inhibitory activity of esculetin isolated from seeds of Euphorbia lathyris L. Biosci Biotechnol Biochem 67: 631-634, 2003

23. Hosoi J, Abe E, Suda T and Kuroki T: Regulation of melanin synthesis of B16 mouse melanoma cells by 1 $\alpha, 25$-dihydroxyvitamin $\mathrm{D}_{3}$ and retinoic acid. Cancer Res 45: 1474-1478, 1985.
24. Pomerantz HS: Tyrosine hydroxylation catalyzed by mammalian tyrosinase: an improved method of assay. Biochem Biophys Res Commun 16: 188-194, 1964

25. Li EPH, Min HJ, Belk RW, Kimura J and Bahl S: Skin lightening and beauty in four Asian cultures. Adv Consum Res 35: 444-449, 2008.

26. Oh EY, Jang JY, Choi YH, Choi YW and Choi BT: Inhibitory effects of 1-O-methyl-fructofuranose from Schisandra chinensis fruit on melanogenesis in B16F0 melanoma cells. J Ethnopharmacol 132: 219-224, 2010.

27. Virador VM, Kobayashi N, Matsunaga $J$ and Hearing VJ: A standardized protocol for assessing regulators of pigmentation. Anal Biochem 270: 207-219, 1999.

28. Hearing VJ and Tsukamoto K: Enzymatic control of pigmentation in mammals. FASEB J 5: 2902-2909, 1991.

29. Busca R and Ballotti R: Cyclic AMP a key messenger in the regulation of skin pigmentation. Pigment Cell Res 13: 60-69, 2000.

30. Momtaz S, Mapunya BM, Houghton PJ, Edgerly C, Hussein A, Naidoo $\mathrm{S}$ and Lall N: Tyrosinase inhibition by extracts and constituents of Sideroxylon inerme L. stem bark, used in South Africa for skin lightening. J Ethnopharmacol 119: 507-517, 2008.

31. Dooley TP: Topical skin depigmenting agents: current products and discovery of novel inhibitors of melanogenesis. J Dermatol Treat 7: 188-200, 1997.

32. Levy C, Khaled M and Fisher DE: MITF: master regulator of melanocyte development and melanoma oncogene. Trends Mol Med 12: 406-414, 2006

33. Sturm RA, O' Sullivan BJ, Box NF, et al: Chromosomal structure of the human TYRP1 and TYRP2 loci and comparison of the tyrosinase-related protein gene family. Genomics 29: 24-34, 1995.

34. Kobayashi T, Imokawa G, Bennett DC and Hearing VJ: Tyrosinase stabilization by Tyrp1 (the brown locus protein). J Biol Chem 273: 31801-31805, 1998.

35. Setaluri V: The melanosome: dark pigment granule shines bright light on vesicle biogenesis and more. J Invest Dermatol 121: 650-660, 2003.

36. Wu H and Park HY: Protein kinase C-beta-mediated complex formation between tyrosinase and TRP-1. Biochem Biophys Res Commun 311: 948-953, 2003

37. Pawelek JM and Chakraborty AK: The enzymology of melanogenesis. In: The Pigmentary System: Physiology and Pathophysiology. Nordlund JJ, Boissy RE, Hearing VJ, King RA and Ortonne JP (eds). Oxford University Press, New York, pp391-400, 1998

38. Manga P, Sato K, Ye L, Beermann F, Amoreux ML and Orlow SJ: Mutational analysis of the modulation of tyrosinase by tyrosinaserelated proteins 1 and 2 in vitro. Pigment Cell Res 13: 364-374, 2000.

39. Hamid MA, Sarmidi MR and Park CS: Mangosteen leaf extract increases melanogenesis in B16F1 melanoma cells by stimulating tyrosinase activity in vitro and by up-regulating tyrosinase gene expression. Int J Mol Med 29: 209-217, 2012.

40. Kim DS, Jeong YM, Park IK, et al: A new 2-imino-1,3-thiazoline derivative, KHG22394, inhibits melanin synthesis in mouse B16 melanoma cells. Biol Pharm Bull 30: 180-183, 2007. 